\title{
Asymmetric Synthesis of anti- and syn-2,3-Diamino Esters using Sulfinimines. Water and Concentration Effects
}

Franklin A. Davis ${ }^{*}$, Yanfeng Zhang, and Hui Qiu

Department of Chemistry, Temple University, Philadelphia, PA 19122

\begin{abstract}

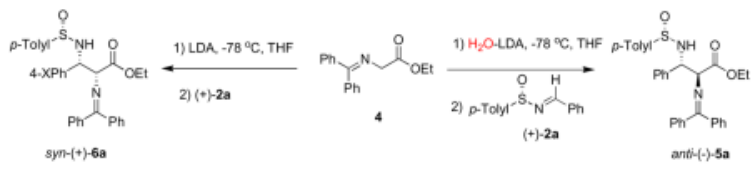

In the absence of water an excess of the lithium enolate of $N$-(diphenylmethylene)glycine ethyl ester (4) adds to sulfinimines to give syn-2,3-diamino esters 6 and in the presence of water this enolate gives the anti-2,3-diamino esters 5. These unusual results are interpreted in terms of those factors that inhibit the retro-Mannich fragmentation in the diamino esters.
\end{abstract}

The beneficial effects of stoichiometric and substoichiometric amounts of water on organic and organometallic reactions have occasionally appeared in the literature and were often the result of serendipitous observations by the investigators. In their excellent review on the subject, Ribe and Wipf grouped these effects into three categories; 1) water as a hydrolyzing agent leading to secondary products that serve as catalysts or promoters; 2 ) water as an internal quenching agent to drive chemical equilibria; and 3) water as a Lewis acid activator or coactivator. ${ }^{1}$ We describe here an unusual example of how water influences the diamino ester anti:syn selectivity resulting from the addition of glycine enolates to sulfinimines ( $\mathrm{N}$-sulfinyl imines).

2,3-Diamino acids are key structural units of biologically active compounds and valuable synthetic intermediates. ${ }^{2}$ In 2004 we disclosed a new one-pot method for the asymmetric synthesis of syn- and anti-2,3-diamino esters (+)-3 and (-)-5a, involving addition of the prochiral lithium enolates of ethyl (dibenzylamino)acetate (1) and $N$-(diphenylmethylene) glycine ethyl ester (4) to $(S)$-(+)- $N$-(benzylidene)-p-toluenesulfinamide (2a) (Scheme 1). ${ }^{3}$ The mechanistic rationale for the high syn/anti selectivity was the formation of the $(E)$ - and $(Z)$ enolates by $\mathbf{1}$ and $\mathbf{4}$, respectively. However, in subsequent studies aimed at exploring and expanding the scope of the methodology for the formation of the anti-2,3-diamino ester $\mathbf{5}$, the reaction became unreliable with the anti/syn selectivity varying from 1:1 to better than 33:1. It soon became evident that the water content in the THF was an important factor determining the selectivity (Table 1).

In the absence of water, all four 2,3-diamino ester isomers were detected by ${ }^{1} \mathrm{H}$ NMR (Table 1, entry 1). However, as the ratio of water to LDA increased there was dramatic improvement in the formation of the anti product reaching a maximum anti:syn ratio of 33:1 and an isolated yield of (-)-5a of $86 \%$ when the $\mathrm{H}_{2} \mathrm{O}: \mathrm{LDA}$ ratio was approximately 1:1 (Table 1, entry 5). As the $\mathrm{H}_{2} \mathrm{O}: \mathrm{LDA}$ ratio increased to $2: 1$, the ratio of $\mathbf{5 a} \mathbf{6} \mathbf{a}$ was maintained along with the yield (Table 1, entry 7). Even when the $\mathrm{H}_{2} \mathrm{O}: \mathrm{LDA}$ ratio was 4:1, the anti:syn ratio was still 33:1, but 
the yield had diminished (Table 1, entry 9). This is a general phenomenon also being observed for sulfinimines derived from aromatic aldehydes having electron withdrawing groups $\mathbf{2 b}(\mathrm{X}$ $=\mathrm{Cl})$ and $\mathbf{2 c}\left(\mathrm{CF}_{3}\right)($ Table 1, entries 16 and 17), and an electron donating group $\mathbf{2 d}(\mathrm{MeO})$ (Table 1, entry 19). Replacement of water with methanol resulted in a 10:1 anti:syn ratio of 5a:6a, but the anti:syn ratio for tert-butanol was 1:1.3 with the other amino ester isomers being detected (Table 1, entries 12 and 13).

Experimentally the reaction was conducted by first cooling the THF- $\mathrm{H}_{2} \mathrm{O}$ solution to $-78{ }^{\circ} \mathrm{C}$ followed by addition of the appropriate amount of LDA. $N$-(Diphenylmethylene)glycine ethyl ester (4), one equivalent in water free THF, cooled to $-78{ }^{\circ} \mathrm{C}$ was then added via cannula to the LDA solution. After stirring at $-78^{\circ} \mathrm{C}$ for $1 \mathrm{~h}, 0.63$ equivalents the sulfinimine $(S)-(+)-2$ in water free THF was introduced at $-78^{\circ} \mathrm{C}$ to the yellow enolate solution. The reaction mixture was quenched after $1.5 \mathrm{~h}$ at $-78{ }^{\circ} \mathrm{C}$ by addition of aqueous $\mathrm{NH}_{4} \mathrm{Cl}$ solution. Diamino esters $(-)-5 a-d$ were isolated by chromatography.

The syn products (+)-6a and (+)-6c were prepared by reacting 5 equivalents of the water free preformed enolate solution of $\mathbf{4}$ with (+)-2a or (+)-2c at a concentration of 0.14 molar. The syn products were isolated in $86 \%$ and $85 \%$ yields, respectively, following chromatography (Table 1, entries 15 and 18). ${ }^{4}$ At lower molar concentration of the enolate, the syn:anti ratio was much poorer (Table 1, entry 14).

The reaction of water with LDA is expected to result in $\mathrm{LiOH}$ and diisopropylamine. However, when the addition reaction was carried out with 1.6 equiv of $\mathrm{LiOH}$ instead of LDA there was no reaction (Table, entry 10). Furthermore, if the $-78^{\circ} \mathrm{C}$ THF-LDA- $\mathrm{H}_{2} \mathrm{O}$ solution is warmed to room temperature for $10 \mathrm{~min}$ and cooled back to $-78^{\circ} \mathrm{C}$ prior to addition of 4 , there is also no reaction (Table, entry 11). As the water content increases the enolate was quenched, albeit slowly, resulting in reduced yields (Table 1 , entries 7,8 , and 9). While these results imply that water and LDA could coexist at $-78^{\circ} \mathrm{C}$, another posssibility is that some LDA-hydroxideisopropylamine aggregate is the active base species.

In the solid state, $\mathrm{X}$-ray crystal structures of lithium enolates show dimers, tetramers, and hexamers. ${ }^{5}$ However, as pointed out by Collum and coworkers, the assignment of such structures in solution is difficult. ${ }^{6}$ For these reasons it is not possible to provide a structure for the $\mathrm{H}_{2} \mathrm{O}-\mathrm{LDA}$ or the enolate species at this time. However, Willard and MacEwan in a study of the cocrystallization of lithium or potassium tert-butoxide with a $\mathrm{Li}^{+}$or $\mathrm{K}^{+}$preformed enolate of 3,3-dimethyl-2-butaone in THF identified a unique aggregated species by $\mathrm{X}$-ray diffraction analysis. This species contained an encapsulated hydroxide at the center of the aggregate. $^{7}$

To determine whether the anti and syn products are formed under kinetic or thermodynamic control they were subjected to treatment with LDA. Reaction of anti-5a at $-78{ }^{\circ} \mathrm{C}$ with 1.1 equiv of LDA in water free THF for $1.5 \mathrm{~h}$ resulted in isomerization and detection of all four amino ester isomers (Table 2, entry 1). There was no effect on the stereochemistry of anti-5a on reaction with $\mathrm{H}_{2} \mathrm{O}$ :LDA (2.5:1) and it was recovered in $77 \%$ yield (Table 2 entry 2). RetroMannich products 2a and $\mathbf{4}$ were also isolated in ca 10\% yield. Similar results were noted for syn-6a with these base combinations. With LDA all four isomers were detected, but with $\mathrm{H}_{2} \mathrm{O}$-LDA the syn isomer was recovered in $80 \%$ in addition to small amounts of the retroMannich products (Table 2, entries 5 an 6). Significantly, when anti-5a was treated with 5 equiv of the glycine enolate syn-6a was isolated in $84 \%$ yield (Table 2, entry 4). However, similar reaction of this enolate with syn-6a had no effect (Table 2, entries 7 and 8).

To explain these novel results we make the reasonable assumption that 7 , the Z-enolate of $\mathbf{4}$, adds to sulfinimine $(S)-(+)-\mathbf{2 a}$ to give the anti-2,3-diamino ester anion $(2 S)$-8, which is the kinetically favored product (Scheme 2) ${ }^{3,8,9}$ The retro-Mannich fragmentation of (2S)-8 
regenerates (+)-2 and enolate 7 and can explain the formation of the various 2,3-diamino ester isomers in water free THF and on reaction of (-)-5a and (+)-6a with 1.1 equiv of LDA (Tables 1 and 2). Retro-Mannich fragmentations of sulfinimine-derived sulfinamide products are usually not observed because the $N$-sulfinyl group stabilizes anions at nitrogen. ${ }^{10,11}$ However, the combination of steric hindrance and the stability of enolate $\mathbf{7}$ favor this fragmentation. When the $\mathrm{H}_{2} \mathrm{O}$-LDA species is used to generate enolate $\mathbf{7}$ it apparently stabilizes the anion at nitrogen in (2S)-8 preventing the retro-Mannich reaction and on work up gives anti-(-)-5a. We suggest that intramolecular chelation in syn-10, which is in equilibrium with anti (2S)-8, is sterically favored over similar chelation in anti-9 inhibiting the retro-Mannich fragmentation in the former. In the presence of enolate $\mathbf{7}$ anti-(-)-5a gives the thermodynamically favored syn product (+)-6a on work-up (Scheme 2).

In summary, manipulation of the water and enolate concentrations makes it possible to prepare either the anti- or syn-2,3-diamino esters (-)-5 or (+)-6, respectively, from a common enolate precursor $N$-(diphenylmethylene)glycine ethyl ester (4) and a chiral sulfinimine. The anti-2,3diamino ester $(-)-5$ is favored under the LDA- $\mathrm{H}_{2} \mathrm{O}$ conditions because the retro-Mannich fragmentation in inhibited. An excess of the enolate of $\mathbf{4}$ provides the thermodynamically favored syn-2,3-diamino ester (+)-6 and is explained in terms of intramolecular chelation in syn-10 that inhibits the retro-Mannich fragmentation.

\section{Supplementary Material}

Refer to Web version on PubMed Central for supplementary material.

\section{Acknowledgements}

We thank David Collum (Cornell University), Martin J. O'Donnell (Indiana Purdue University), David Dalton (Temple University), Scott Sieburth (Temple University), and Paul Williard (Brown University) for helpful discussions. Additionally, we thank J. Deng (Temple University) for preliminary studies and H. Zhang (Temple University) for aid with the Karl Fisher titrations. NIH-NIGMS (GM57870) supported this work.

\section{References}

1. Ribe S, Wipf P. Chem Commun 2001:299.

2. Viso A, Fernandez de la Pradilla R, Garcia A, Flores A. Chem Rev 2005;105:3167. [PubMed: 16092828]

3. Davis FA, Deng J. Org Lett 2004;6:2789. [PubMed: 15281770]

4. The syn stereochemistry of (+)-6a was determined as previously described in reference ${ }^{3}$.

5. Seebach D. Angew Chem Int Ed 1988;27:1624.

6. McNeil AJ, Toombes GES, Gruner SM, Lobkovsky E, Collum DB, Chandramouli SV, Vanasse BJ, Ayers TA. J Am Chem Soc 2004;126:16559. [PubMed: 15600361]

7. Williard PG, MacEwan GJ. J Am Chem Soc 1989;111:7671.

8. The lithium enolate of 4 is generally considered to have the (Z)-geometry as a consequence of intramolecular chelation of the lithium ion with both the enolate oxygen and the pair of electrons on the $\mathrm{sp}^{2}$ nitrogen atom. Numerous experimental results have been rationalized in terms of this chelated enolate structure. See (a) McIntosh JM, Leavitt RK, Mishra P, Cassidy KC, Drake JE, Chadha R. J Org Chem 1988;53:1947. and references cited there in (b) Alvarez-Ibara C, Csaky AG, Colmenero B, Ouiroga ML. J Org Chem 1997;62:2478. [PubMed: 11671585] (c) Ezquerra J, Pedregal C, Merino I, Florez J, Barluenga J, Garcia-Granda S, Llorca MA. J Org Chem 1999;64:6554. [PubMed: 11674657] (d) Ref. 2.

9. (a) O’Donnell MJ. Acc Chem Res 2004;37:506. [PubMed: 15311949] (b) O'Donnell MJ. Aldrichimica Acta 2001;34:3.

10. For leading references see (a) Zhou P, Chen BC, Davis FA. Tetrahedron 2004;60:8003. (b) Davis FA. J Org Chem 2006;71:8993. [PubMed: 17109522]

Org Lett. Author manuscript; available in PMC 2008 September 12. 
11. For recent reviews on the chemistry of sulfinimines see: (a) Morton D, Stockman RA. Tetrahedron 2006;62:8869. (b) Senanayake CH, Krishnamurthy D, Lu ZH, Han Z, Gallou I. Aldrichimica Acta 2005;38:93.. (c) Ref. 9. (d) Ellman JA, Owens TD, Tang TP. Acc Chem Res 2002;35:984. [PubMed: 12437323] 


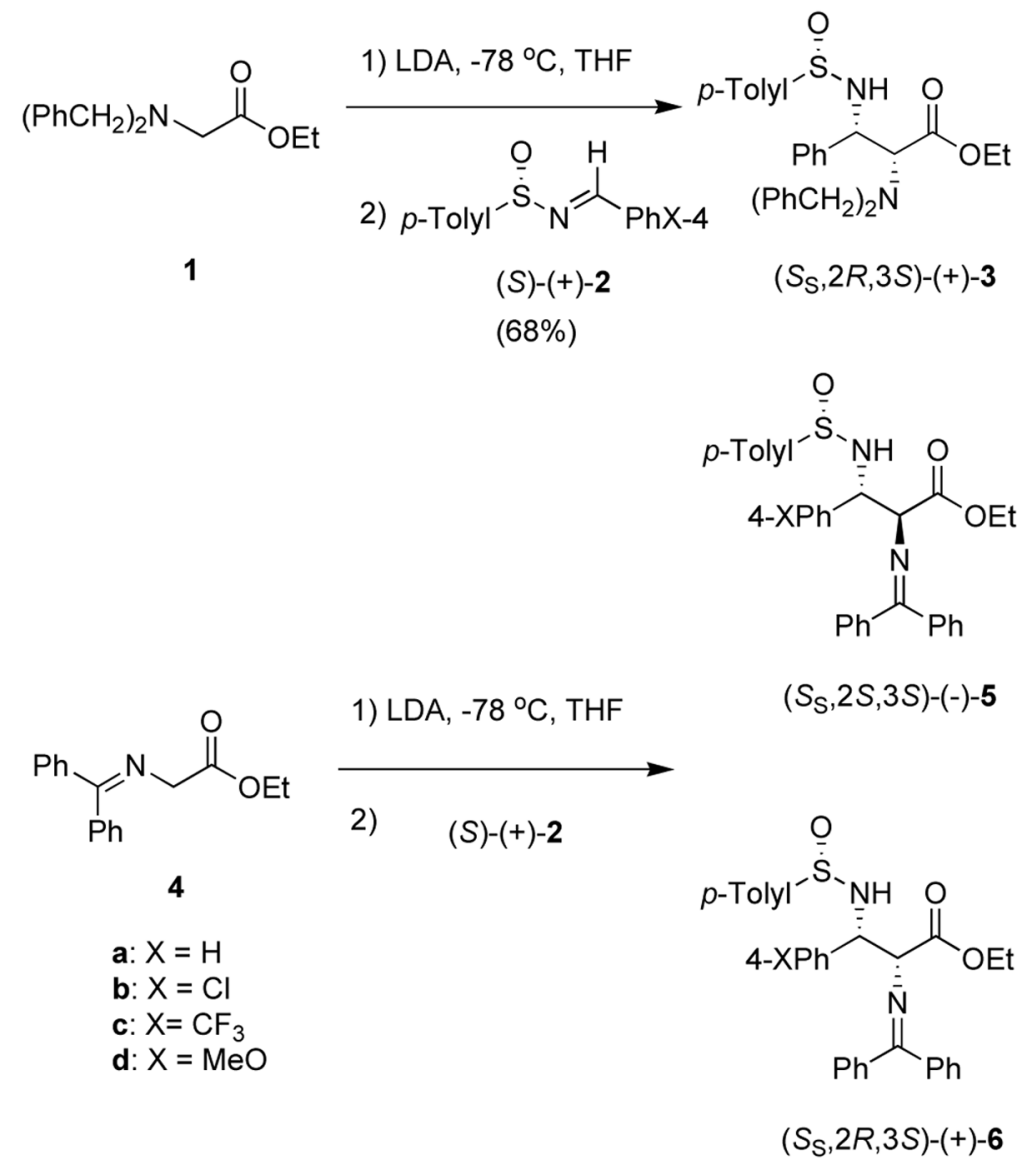

Scheme 1. 

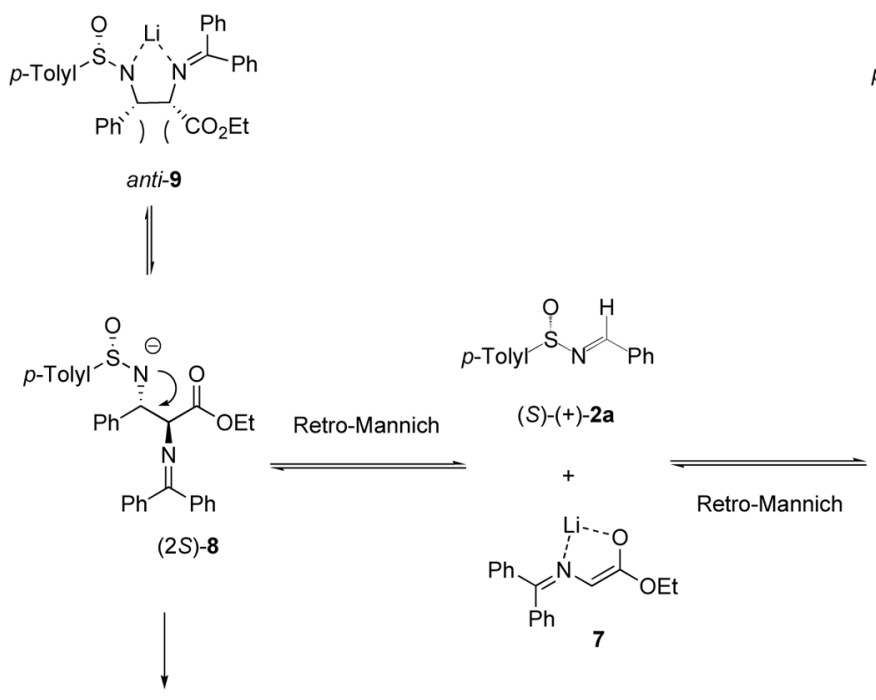

$\left(S_{S}, 2 S, 3 S\right)-(+)-5 \mathbf{a}$
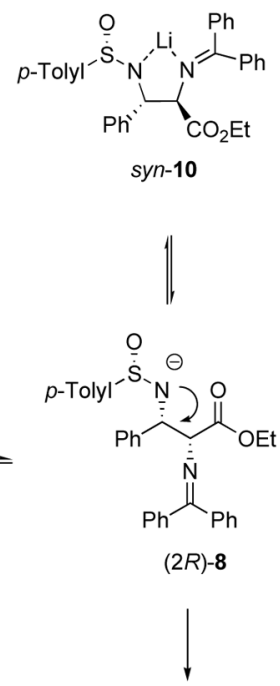

$\left(S_{S}, 2 R, 3 S\right)-(+)-6 \mathbf{a}$

Scheme 2.

Org Lett. Author manuscript; available in PMC 2008 September 12. 
Table 1

The influence of water on the formation of anti-2,3-diamino ester (-)-5. ${ }^{a}$

\begin{tabular}{|c|c|c|c|c|}
\hline \multirow{2}{*}{$\begin{array}{l}\text { entry } \\
1\end{array}$} & \multicolumn{2}{|c|}{ 2, (X) $\mathrm{H}_{2} \mathrm{O}^{b \mathrm{LDA} c}$ ratio } & \multirow{2}{*}{$\begin{array}{l}\text { anti/syn ratio }^{d} \\
1: 1\end{array}$} & \multirow{2}{*}{$\begin{array}{l}5: 6 \% \text { yield }^{e} \\
f\end{array}$} \\
\hline & $2 \mathbf{a}(\mathrm{H})$ & $0: 1$ & & \\
\hline 2 & & $0.5: 1$ & $1: 1$ & $f$ \\
\hline 3 & & $0.7: 1$ & $16: 1$ & 80 \\
\hline 4 & & $0.98: 1$ & $25: 1$ & 86 \\
\hline 5 & & $1.09: 1$ & $33: 1$ & 86 \\
\hline 6 & & $1.35: 1$ & $33: 1$ & 86 \\
\hline 7 & & $2.0: 1$ & $33: 1$ & 85 \\
\hline 8 & & $3.1: 1$ & $33: 1$ & 78 \\
\hline 9 & & $3.9: 1$ & $33: 1$ & 60 \\
\hline 10 & & $\mathrm{LiOH}^{g}$ & no reaction & $h$ \\
\hline 11 & & 2.0:1 $1^{i}$ & no reaction & $h$ \\
\hline 12 & & $1.5: 1 \mathrm{MeOH}^{j}$ & $10: 1$ & $f$ \\
\hline 13 & & $1.5: 1 t-\mathrm{BuOH}^{j}$ & $1: 1.3$ & $f$ \\
\hline 14 & & $0: 1^{k}$ & $1: 5$ & $f$ \\
\hline 15 & & $0: 1, k l$ & $1: 33$ & 86 \\
\hline 16 & $\mathbf{2 b}(\mathrm{Cl})$ & $1.9: 1$ & $25: 1$ & 80 \\
\hline 17 & $2 c\left(\mathrm{CF}_{3}\right)$ & $2.0: 1$ & $25: 1$ & 87 \\
\hline 18 & $2 \mathbf{c}\left(\mathrm{CF}_{3}\right)$ & $0: 1, k l$ & $1: 25$ & 85 \\
\hline 19 & $2 d(\mathrm{MeO})$ & $1.9: 1$ & $25: 1$ & 85 \\
\hline
\end{tabular}

\footnotetext{
$a_{\text {These results are the average of at least two experiments. }}$

$b_{\text {The water content was determined by Karl Fisher titration. }}$

${ }^{c}$ Enolate concentration was 0.02 molar unless otherwise noted.

${ }^{d}$ Determined by ${ }^{1}$ H NMR on the crude reaction mixture.

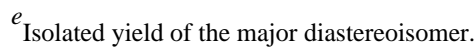

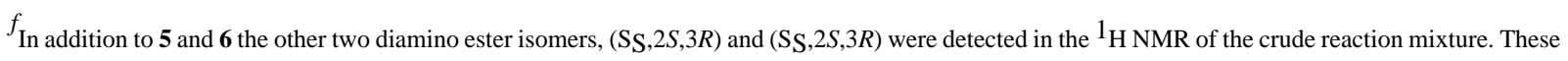
isomers could not be separated.

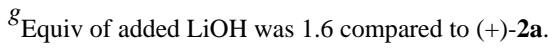

$h_{\text {Starting materials were recovered. }}$

${ }^{i}$ The $-78{ }^{\circ} \mathrm{C}$ water-THF-LDA solution was warmed to $\mathrm{rt}$ for $10 \mathrm{~min}$ and cooled back to $-78^{\circ} \mathrm{C}$ prior to addition of 4 .

${ }^{j}$ Alcohol was used in the place of water.

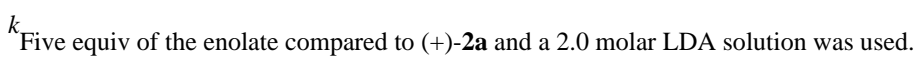

${ }^{l}$ Enolate concentration was 0.14 molar. .
} 
Table 2

Reaction of anti-5a and syn-6a with bases at $-78{ }^{\circ} \mathrm{C}$ for $1.5 \mathrm{~h} .{ }^{a}$

\begin{tabular}{|c|c|c|c|}
\hline entry & diaminoester & $\begin{array}{l}\text { conditions(equiv of LDA to } 5 \text { a or } \\
6 \text { a) }\end{array}$ & products $[\% \text { yield }]^{b c}$ \\
\hline 1 & \multirow[t]{4}{*}{ anti-5a } & LDA $(1.1: 1)$ & \multirow{2}{*}{$\begin{array}{l}\text { 5a:6a:other isomers }(10: 9: 6: 8)^{d}[80], \mathbf{2 a}[9], \mathbf{4}[9] \\
\text { 5a [77], 2a [10], } \mathbf{4}[10]\end{array}$} \\
\hline 2 & & $\mathrm{H}_{2} \mathrm{O}-\mathrm{LDA}^{e}(1.1: 1)$ & \\
\hline 3 & & LDA-4 $f_{f}(1.1: 1)$ & 5a:6a:other isomers $(5: 1: 1: 1)^{d}[82]$ \\
\hline 4 & & LDA-4 $(5: 1)$ & $\mathbf{6 a}[84]$ \\
\hline 5 & \multirow[t]{4}{*}{ syn-6a } & $\operatorname{LDA}(1.1: 1)$ & \multirow{4}{*}{$\begin{array}{l}\mathbf{5 a : 6 a : o t h e r ~ i s o m e r s ~}(10: 10: 5: 8)^{d}[86] \mathbf{2 a}[6], \mathbf{4}[6] \\
\mathbf{6 a}[80], \mathbf{2 a}[10], \mathbf{4}[10] \\
\mathbf{6 a}[84] \\
\mathbf{6 a}[90]\end{array}$} \\
\hline 6 & & $\mathrm{H}_{2} \mathrm{O}-\mathrm{LDA}^{e}(1.1: 1)$ & \\
\hline 7 & & LDA-4 $f_{(1.1: 1)}$ & \\
\hline 8 & & $\operatorname{LDA}_{-4}{ }^{\prime}(5: 1)$ & \\
\hline
\end{tabular}

\footnotetext{
${ }^{a}$ Water free THF used unless otherwise noted.

${ }^{b}$ Determined integration the $p$-tolyl methyl on the crude reaction mixtures.

$c_{\text {Isolated yield. }}$

$d_{\text {Isomers could not be separated. }}$

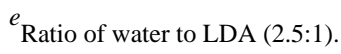

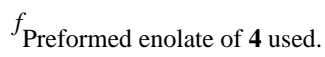

